\title{
XLV Anniversary of the Mexican Council of Psychiatry
}

\author{
Ricardo Colin-Piana, ${ }^{1}$ Jesús María del Bosque-Garza, ${ }^{1}$ Martha Patricia Ontiveros-Uribe ${ }^{1}$
}

\begin{abstract}
1 Consejo Mexicano de Psiquiatría 2016-2017.

Correspondence:

Martha Patricia Ontiveros-Uribe Consejo Mexicano de Psiquiatría, Edificio de Gobierno, primer piso, Instituto Nacional de Psiquiatría Ramón de la Fuente Muñiz.

Calz. México-Xochimilco 101, Col.

San Lorenzo Huipulco, Del. Tlalpan, C.P. 14370, Ciudad de México

Mexico, México.

Phone: 4160 - 5229

Email: ontiverosmartha@yahoo.

com.mx
\end{abstract}

Received first version: June 12, 2017 Second version: September 19, 2017 Accepted: September 25, 2017

doi.10.17711/SM.0185-3325.2017.030

\begin{abstract}
SUMMARY
The Mexican Council of Psychiatry is celebrating this year its 45th anniversary. It is one of the first specialized medical councils in the country, and to date has certified 2532 psychiatric specialists. This article recounts how the Council was founded, the contributions that more than 40 Mexican psychiatrists have made to its consolidation over the years, and the outlook of its work for the future.
\end{abstract}

Keywords: Mexican, council, psychiatry, history, present.

\section{RESUMEN}

El Consejo Mexicano de Psiquiatría celebra este año su aniversario 45. Se trata de uno de los primeros consejos médicos de especialidad en el país, y a la fecha ha emitido constancia de certificación a 2532 especialistas en psiquiatría. En este artículo se relata su historia fundacional, la contribución de más de 40 psiquiatras mexicanos a su consolidación a lo largo de los años y la perspectiva de sus trabajos hacia el futuro.

Palabras clave: Consejo, mexicano, psiquiatría, historia, actualidad.

\section{BACKGROUND}

Societies have always strived to guarantee that their doctors and other professionals have sufficient knowledge and skill to be considered reliable by the general population. Since Hammurabi's Code (1769 BCE), states have issued laws and regulations to ensure this. Medical knowledge has been strengthened by the spectacular developments in science since the late $19^{\text {th }}$ century. Technology is now an indispensable tool for diagnosis and therapeutics, and it uses increasingly daring processes. Contemporary society is more informed than ever, demanding that their doctors and collaborators be fully trained, but who should be authorized to judge the capacity and continuing professional development of highly-trained professionals such as medical specialists? Society has answered this question by delegating this task to their medical peers.

With this idea in mind, the American Board of Ophthalmology was founded in the United States in 1916, followed by other medical specialties over the years. The example was set and spread to other countries. England and its colonies founded Royal Colleges for the same purpose.

Mexico began this process in 1963 by founding the Mexican Council of Medical Pathologists, and subsequently the Mexican Council on Neurosurgery (1965), the Mexican Urology (1968), the Mexican Council on Plastic Surgery (1969), and the Mexican Council on Otolaryngology (1970). In the early 1970s, councils for gynecology and obstetrics, pneumology, neurology and psychiatrics were also founded.

By 1974, fifteen different councils for other specialties had been set up, which sought support and guidance from the National Academy of Medicine. The Academy accepted its role as the coordinating and normative body, and began to certify physicians.

The Mexican Academy of Surgery followed suit in 1995 as the advisory board for the federal government and as a member of the General Health Council. The various Medical 
Specialty Councils were then convened to create an assembly, and the National Advisory Committee of Medical Specialization Councils (CONACEM) was formed on February 15, 1995.

The goal of certification was to create a board comprised of peers, and accredit practitioners' capacity and experience in the use of the corresponding procedures and techniques in keeping with the Lex Artis Ad Hoc of each area of specialization.

The purpose of this article is to describe the history of the founding of the Mexican Council of Psychiatry, its evolution over the past forty-five years, and the modernization of its procedures to update and monitor the continuous professional development of specialists in psychiatric medicine.

To this end, a review of the Council's historical archives was conducted, where most of the records drawn up by secretary-treasurers since 1972 are stored (Minutes of Ordinary Meetings of the Mexican Council of Psychiatry, 1972-2017).

\section{FOUNDING THE MEXICAN COUNCIL OF PSYCHIATRY}

On March 24, 1972, during an ordinary meeting of the Board of the Mexican Association of Psychiatry (MAP), Dr. Darío Urdapilleta Bueno, the incumbent president, informed the board that a council of specialists would be summoned according to the existing guidelines.

The MAP asked the National Academy of Medicine to suggest two academics from the field of psychiatry to form part of this council, and agreed to name their incumbent president and Dr. Ramón de la Fuente Muñiz as MAP representatives. They also agreed to ask the main psychiatric groups to do the same.

The MAP's Specialization Certification Committee declared that the specialization councils should be guided by the following fundamental principles:
1. Seek exclusively to specify the knowledge and skills required for exercising a medical specialty, and certify those who possessed them.

2. Universally certify all those who, having met the criteria, voluntarily requested certification.

3. Exclusively serve areas of medicine where medical acts take place, in other words, where patients request the assistance of a physician to relieve their symptoms.

4. Only consider actions beyond the scope of general practitioners, or actions in previously-recognized areas of specialization. The Academy itself will determine which specialties should receive recognition.

It also defined the criteria to be met by the councils:

1. The group should be exclusively comprised of specialized surgeons who constitute a representative group of the specialty in various geographical areas and institutions where this specialty is practiced.

2. There can only be one council per medical specialty.

3. The council will have the following exclusive goals:

a. Establish minimum educational requirements for specialists in a given branch of medicine with the goal of guaranteeing the quality of the services they provide.

b. Provide certification to specialists who voluntarily request it and meet the established requirements.

c. Approve training programs and ensure they meet the requirements for specialization training.

d. Evaluate and sanction continuous professional development programs for specialists.

e. It will not be the function of the councils to organize courses, seminars, other teaching programs, or other types of scientific or social activities.

The Mexican Council of Psychiatry was founded in Mexico City on June 8, 1972. At the MAP's behest, they brought together representatives from the National Academy of Medicine's Psychiatry Department, the Mexican Neurology and Psychiatry Society, and the Mexican Biological Psychiatry Society (Pérez-Rincón, 1995).

Table 1

Founding Directors of the National Council of Psychiatry

\begin{tabular}{ll}
\hline National Academy of Medicine & Dr. Guillermo Calderón Narváez \\
Mexican Association of Psychiatry, A.C. & Dr. Agustín Caso Muñoz \\
Mexican Society of Neurology and Psychiatry & Dr. Damón de la Fuente Muñiz \\
& $\begin{array}{l}\text { Dr. Dionisio Nieto Gómez } \\
\text { Dr. Jorge Velasco Alzaga }\end{array}$ \\
Mexican Society of Biological Psychiatry & Miguel Ángel Pérez Toledo \\
Representatives around the country & Dr. José Carranza Acevedo \\
& Dr. Manuel Camelo Martínez \\
& Dr. Javier del Valle Gómez \\
& Dr. Everardo Neumann Peña \\
& Dr. Rafael Velasco Fernández \\
\hline
\end{tabular}


During its initial stage, each council realized the need to design a protocol that would allow a first group of specialists to form a panel to determine which of their colleagues met the necessary requirements for being accredited as a specialist. Although each council solved the matter according to the demands of each specialty, they were all guided by general criteria. For example, each founding member had to be a leading specialist in the field with sufficient moral authority. Moreover, the group of Director Members should represent the most important sectors of the specialty and the council must have been acknowledged by the National Academy of Medicine.

The Founding Members were tasked with drawing up the Articles of its Constitution, formulating the general statutes and launching the call for specialists in psychiatric medicine residing in Mexico who met the requirements to submit their resumes for certification.

The first call for certification was widely published in the national press, specialized medical journals, and psychiatric societies, to such an extent that it would have been impossible for a specialist living in Mexico to be unaware of it.

The Director Members, according to the general statutes, allowed specialists to receive certification without an evaluation exam for the first four years, in order to consolidate the council as an institution.

By April 1979, the Director Members had favorably validated the professional credentials of thirty colleagues and the council comprised forty-six specialists. By November 30 that same year, Undersecretary of Health and Welfare Carlos Campillo Sainz presented the first certificates at a ceremony held in the auditorium of the National Academy of Medicine.

The council decided to hold four working meetings a year and the presidency would be determined on a rotating, alphabetical basis according to each director's surname.

Until then, the protocol used in the working sessions involved the presentation of the resumes of the psychiatrists, who, having been invited, agreed for their professional credentials to be validated. Candidates were admitted to the council through a majority of votes. However, since there were differences of opinion amongst the Director Members, Dr. Agustín Caso Muñoz proposed a rule that increased the minimum number of votes required to accept a proposal to nine.

At the September 1976 meeting, the directors concluded that "there were still some specialists meeting the certification criteria for whom an exam would be unnecessary." They therefore tasked the Secretary-Treasurer with inviting them to request admission.

During the last meeting in 1976, as in every meeting, the directors discussed the credentials of the thirteen candidates submitted for certification. Many members observed that "the period of certifying candidates without an exam had continued for too long." Other directors agreed with this opinion, but insisted that despite "the widespread publicity provided by the Council", there could still be a number of specialists unaware of the possibility of certification. At that stage, the Council comprised 224 certified psychiatrists. A deadline was set for March 1977, after which candidates would no longer be certified without an examination.

They formed an "ad hoc" committee to design the first exam comprising the directors: Ramón de la Fuente Muñiz, Carlos Campillo Serrano, Manuel Isaías López Gómez, Carlos Pucheu Regis, and Jorge Velasco Alzaga.

Furthermore, as agreed at previous meetings, they invited Dr. Dionisio Nieto Gómez to join the committee.

The first call for certification by exam was launched in the MAP's official journal Psychiatría, volume 6, number 3, September-December 1976. There were two exams, one covering theoretical knowledge (to be held on October 5, 1977) and one on clinical knowledge and practical skills (to be held in late November, 1977) (Official Body of the Mexican Psychiatric Association, 1976).

The results of the Mexican Council of Psychiatry's first exam were as follows: 42 applications were received, five of which were eliminated for not meeting the criteria. Twenty-nine doctors took the theory exam. This exam included two hundred multiple choice questions and twenty open-ended questions. It was held in the auditorium at the UNAM Medical Faculty's Department of Medical Psychology and Mental Health and lasted for six hours. Four candidates failed the theory exam. The judges also required the first group of psychiatrists who took the clinical skills tests to take a viva exam.

Diplomas were presented on April 21, 1978, in the auditorium of the Fray Bernardino Álvarez Psychiatric Hospital. Dr. Agustín Caso Muñoz, the incumbent president, gave the welcome speech and then Dr. Fernando Isunza, the representative of the nine members spoke, followed by Dr. Mario Fuentes Delgado, representing the Department of Health and Welfare. Lastly, diplomas were presented by Dr. Octavio Rivero Serrano, then director of the UNAM School of Medicine.

During the directors' meeting on June 8, 1978, Dr. Manuel Isaías López Gómez argued on behalf of the Pediatric Psychiatry Commission that practitioners of this specialty should also be certified by the council. The academic credentials of forty specialists were therefore submitted for review, in response to the public request to form the first certified group in this discipline. The Director Members examined the documentation and agreed it was unnecessary for the thirty-six applicants to take an exam and accepted them as specialists.

In March 2016, the board drafted a certification protocol for the first group of doctors with valid certification in psychiatry and specialists in sleep medicine. In keeping with the Council's tradition, it was decided that on this oc- 
casion alone, certification evaluation for this area of specialty would be exclusively based on an evaluation of the candidates' academic credentials. The call for submissions was launched and ten applicants responded, each of whom was granted certification a few months later.

The exam on theoretical knowledge and clinical cases is now the principal accreditation instrument used by the Council to validate candidates. Director Members have created a bank of questions over the past thirty years, which the directors can use when designing the examinations, which are now comprised of 300 questions divided into three sections: the first two sections each contain 100 theoretical questions and the third section is made up of serialized clinical cases.

In recent years, the Council has hired a group of UNAM-trained pedagogical experts to determine the quality of the exams to guarantee both quality and objectivity. Each exam item is graded according to its index of difficulty $(\mathrm{P})$, reliability (Cronbach's alpha) and discrimination (Rpbis).

The collection of grades describes the level of difficulty of the exam, its reliability, and its ability to act as an assessment tool for distinguishing between those who possess sufficient knowledge from those who do not. The exams are consistently rated as moderately difficult, with acceptable levels of discrimination and sufficient reliability.

At the time of writing, the Council has issued 2,590 certificates for doctors in this specialty. In the early years of the Council's existence, 224 of these doctors were certified solely on the basis of their academic credentials with the rest being accredited on the basis of the knowledge and clinical skills exams. The Council's website currently lists 1,251 specialists with valid certifications, equivalent to approximately a quarter of Mexico's total population of psychiatrists.

The Council has been evaluating candidates twice a year in March and October for a number of years and continuously renews certification by rating academic credentials every five years. There is an increasing number of psychiatrists interested in keeping their certifications up-to-date. These days, most public and private hospitals in Mexico require their specialists to be affiliated to the Council and have valid certifications. Being certified implies aligning one's work with norms set forth by the Law of General Health, modified on September 1, 2011 to indicate that:

Article 81. Health and higher education institutions are responsible for issuing medical specialization diplomas officially recognized by the corresponding authorities. In order to perform specialized medical interventions, every specialist must be trained in medical or surgical procedures at health institutions officially accredited by the corresponding authorities. The National Advisory Committee for Medical Specialization Councils will be a Federal Public Administration agency, responsible for supervising the training, skills, expertise, and qualifications required for certification and recertification in the various medical specialties recognized by the Committee. It will also supervise health institutions previously recognized by corresponding authorities. The Medical Specialization Councils that have been declared suitable and have been recognized by the National Advisory Committee for Medical Specialization Councils, comprising the Mexican National Academy of Medicine, the Mexican Academy of Surgeons, and member Specialization Councils, are authorized to issue certificates within their respective areas of expertise. In order to issue special medical licenses, the competent educational authorities must request an opinion from the Advisory Committee to the Council on Medical Specialization.

Article 83. Those who engage in professional, technical, or auxiliary activities and a medical specialty should publicly display a certificate indicating the institution which issued their title, diploma, and professional license number in addition to a current specialization certificate. This information should be included in all documents and stationery used by the doctor when exercising professional activities and in all related publicity.

Article 272 Bis. In order to perform a specialized surgical intervention, the professional must: I. Hold a special practice license legally issued by competent educational authorities. II. Possess a current specialization certificate accrediting competence and experience in carrying out the necessary procedures and techniques in compliance with the Lex Artis Ad Hoc for each specialization. This should be issued by the corresponding specialization Council in accordance with article 81 of this law. Medical specialists may belong to medical groups whose fundaments and protocols are coordinated by special professional associations, societies, schools, or federations; these groups should uphold and encourage professionalism and ethical behavior among medical practitioners. The National Advisory Committee to the Councils on Medical Specialization must adhere to the provisions stipulated by the Ministry of Public Health for the application of this article and provisions in the Fourth Title of this law (ordinance to reform articles 81, 83, 271, and add article 272 Bis, 272 Bis, 272 Bis2, 272 Bis 3 of the General Health Law, 2011).

\section{CONCLUSION}

Thus, being certified by the Council and renewing this certificate, implies, among other things, complying with Mexico's laws. This will grant the subject access to public and private sector jobs as a psychiatric specialist, and in teaching or researching psychiatric and mental health. The medical specialist certificate also provides higher levels of protection against action from authorities should any dispute arise. Lastly, people who use psychiatric services in- 
creasingly demand current certification from their doctors as proof of their continuous professional development and peer recognition.

Forty-five years after its inception, the Mexican Council of Psychiatry is a solid institution provided for psychiatrists to guarantee the quality and up-to-date nature of its members' work.

\section{REFERENCES}

Decreto por el que se reforman los artículos $81,83,271$ y se adicionan el artículo 272 Bis, 272 Bis 1, 272 Bis 2, 272 Bis 3 de la Ley General de Salud. (01-092011). Diario Oficial de la Federación (Segunda Sección), 1-2. Poder Ejecutivo, Secretaría de Salud.

Pérez-Rincón, H. (1995). Breve Historia de la Psiquiatría en México. Ciudad de México: Publicaciones del Instituto Mexicano de Psiquiatría. 